\title{
Epigenetic Reprogramming Induced Pluripotency
}

\author{
Anna Meiliana ${ }^{1,2 *}$ and Andi Wijaya ${ }^{1,2 *}$
}

\begin{abstract}
'Post Graduate Program in Clinical Biochemistry, Hasanuddin University, Jl. Perintis Kemerdekaan Km.10, Makassar, Indonesia ${ }^{2}$ Prodia Clinical Laboratory, Jl. Cisangkuy No.2, Bandung, Indonesia

Correspondence: anna_m@prodia.co.id, andi_w@prodia.co.id
\end{abstract}

\section{Abstract}

$\mathrm{B}$

ACKGROUND: The ability to reprogram mature cells to an embryonic-like state by nuclear transfer or by inducing the expression of key transcription factors has provided us with critical opportunities to linearly map the epigenetic parameters that are essential for attaining pluripotency.

CONTENT: Epigenetic reprogramming describes a switch in gene expression of one kind of cell to that of another unrelated cell type. Early studies in frog cloning provided some of the first experimental evidence for reprogramming. Subsequent procedures included mammalian somatic cell nuclear transfer, cell fusion, induction of pluripotency by ectopic gene expression, and direct reprogramming. Through these methods it becomes possible to derive one kind of specialized cell (such as a brain cell) from another, more accessible tissue, such as skin in the same individual. This has potential applications for cell replacement without the immunosuppression treatments commonly required when cells are transferred between genetically different individuals.

SUMMARY: Reprogramming with transcription factors offers tremendous promise for the future development of patient-specific pluripotent cells and for studies of human diseases. The identification of optimized protocols for the differentiation of iPS cells and ES cells into multiple functional cell types in vitro and their proper engraftment in vivo will be challenged in the coming years. Given that the first small-molecule approaches aimed at activating pluripotency genes have already been devised and that murine iPS cells have recently been derived by using non-integrative transient expression strategies of the reprogramming factors, we expect that human iPS cells without permanent genetic alterations will soon be generated.

KEYWORDS: Epigenetics, Reprogramming, Pluripotency, Stem Cells, iPS Cells, Chromatin, DNA Methylation.

Indones Biomed J 2011 ; 3 (2) : 93-109

\section{Introduction}

For almost ten years, since 1997 when the cloned sheep Dolly was first announced until the advent of human induced pluripotent stem cells (iPS cells) in $2007(1,2)$, the field has struggled with the ethical challenge posed by the idea of creating patient-specific embryonic stem cells (ESCs )via somatic cell nuclear transfer (SCNT) (3). Indeed, when Takahashi et al. (2007) and Yu et al. (2007) announced the generation of human iPS cells, a collective sigh of relief was almost audible, as the field embraced an approach that promised to bypass the need for human embryos $(2,4)$.

Manipulating cells from adult human tissue, scientists have generated cells with the same developmental potential as embryonic stem cells. The research opportunities these exciting observations offer are limitless. Several questions about the mechanism of the reprogramming process arise from these exciting observations (2,4-6). 
The cells in a multicellular organism have nominally identical DNA sequences (and therefore the same genetic instruction sets), yet maintain different terminal phenotypes. This non-genetic cellular memory, which records developmental and environmental cues (and alternative cell states in unicellular organisms), is the basis of epi-(above)-genetics.

The lack of identified genetic determinants that fully explain the heritability of complex traits, and the inability to pinpoint causative genetic effects in some complex diseases, suggest possible epigenetic explanations for this missing information. This growing interest, along with the desire to understand the "deprogramming" of differentiated cells into pluripotent/totipotent states, has led to "epigenetic" becoming shorthand for many regulatory systems involving DNA methylation, histone modification, nucleosome location, or noncoding RNA.

So what is epigenetics? An epigenetic system should be heritable, self-perpetuating, and reversible. Epigenetic mechanisms allow cells to adjust gene expression in response to environmental cues. Increased understanding of this area has led to excitement in the scientific community about the potential of applying epigenetic regulation to drug discovery and new treatment options.

Epigenetic changes are not related to alterations in DNA sequences, but instead are the result of stable modifications to chromatin, DNA or protein conformation. These modifications are introduced by specific enzymes and most of the scientific focus to date has been on histone deacetylases and DNA methyltransferases-enzymes that have roles in potentialy critical regulatory events in mamalian gene expression.

Epigenetics is the study of heritable changes in gene expression that occur independently of alterations in the primary DNA sequence. Normal development requires a carefully orchestrated epigenetic program on both a global and gene-specific/tissue-specific level (7). Epigenetic regulation of gene expression, which refers to stable and heritable changes in gene expression potential, is essential for normal embryonic development and cellular differentiation. Epigenetic mechanisms provide a memory of developmental history of a cell, and are also responsive to environmental inputs. These extracellular cues serve to direct programs of gene expression that restrict developmental potency as the organism proceeds from a totipotent single cell to a fully mature state. Mounting experimental evidence suggests that epigenetic modifications, either DNA methylation or posttranslational modification of histones, are functionally required for establishing and maintaining heritable states of gene expression.
The importance of epigenetic control in developmental regulation of stem cells supports the notion that similar mechanisms regulate adult tissue homeostasis at the level of adult stem cells. Altered cellular plasticity may be a general mechanism through which aberrant epigenetic programs exert their effects. Loss of epigenetic control can lead to reduced self-renewal and accelerated aging of stem cells. Conversely, enhanced self-renewal through epimutation in tissue stem cells, or reacquisition of stem cell expression states by faulty reprogramming mechanisms are thought to represent early events in cancer. The inherent reversibility of these epigenetic states provides a potential therapeutic opportunity to reset the balance of tissue homeostasis through these pathways (8).

iPS cells provide a unique platform to dissect the molecular mechanisms that underlie epigenetic reprogramming. Moreover, iPS cells can teach us about principles of normal development and disease, and might ultimately facilitate the treatment of patients by customtailored cell therapy.

\section{Epigenome and Epigenetic}

The "epigenome" comprises a range of modifications that are imposed on the genome (DNA) and ensure the stable transmission of gene expression patterns without changes to the DNA sequence. "Epigenetic disruptors" could change gene activity and in the case of stem cells, alter cell fate or number, causing, for example, an increased risk of cancer (11). "Epimutations" arising in this way may even pass through the germ line to the gametes, thereby affecting subsequent generations. Due to their inherent developmental plasticity, stem cells may be an ideal reporter system for epigenetic perturbations. This could be achieved by studying loci (such as imprinted genes) that undergo epigenetic alterations in normal development, and monitoring their response to potentially disruptive agents.

In the conventional, static model, epigenetic stability is proportional to the amount of DNA methylation and histone modifications. In the dynamic model, the steady turnover of epigenetic modifications makes the epigenome persistently vulnerable (11). Recent findings shed some light on the mechanistic basis of this epigenetic vulnerability and may challenge the current view of DNA methylation as a stable epigenetic modification. DNA methylation appears subject to constant and dynamic turnover-for example, through conversion of 5-methyl 
cytosine into 5-hydroxymethyl cytosine-highlighting the possibility that DNA methylation patterns have to be actively maintained during each cell division cycle (9-11).

Human genomes consist of the DNA encoding our genetic information, whereas epigenomes include DNA modifications and histone modifications layered on top of the genome. These marks comprise a part of the instructions directing the genome to express genes at particular places and times (12,13). Scientific understanding of the DNA 'hardware' of the human genome is well established, but the epigenomic 'software' has not yet been systematically investigated at a genome-wide level. A chief hurdle for such an endeavor is the large number of epigenomes even within an individual. Each of us has essentially one genome; however, each cell type in each individual is believed to have a distinct epigenome that reflects its developmental state (14). Thus, there are likely to be at least as many human epigenomes as there are distinct cell types in the human body.

The epigenetic state of a cell is affected by developmental as well as environmental influences, and both of these inputs may leave epigenetic traces that the cell 'remembers' (referred to as cellular memory) (15). Furthermore, the history of transcription and environmental influences, such as nutrition, toxins, drugs of abuse, infection, disease state and exposure to toxic agents, can also affect DNA and histone modifications (16). Thus, the epigenome may provide a crucial interface between the environment and the genome. The stability of chromatin changes can vary: some may be transient changes, whereas others are longer lasting. Some chromatin changes are mitotically heritable and can affect somatic tissues, whereas others may even be inherited through meiosis and affect the next generation (17). Epigenetic states are also likely to be influenced by an individual's specific constellation of genetic variation; however, the extent to which this is the case is unknown. Thus, there is potentially an extremely large number of possible epigenomes that could be mapped. The field of epigenomics - the study of epigenetic changes at the level of the genome- has changed rapidly, largely owing to advances in DNA sequencing technology (18).

Large-scale epigenomic mapping studies have the potential to enhance three major areas of science: basic gene regulatory processes, cellular differentiation and reprogramming, and the role of epigenetic regulation in disease. Although chromatin modifications are becoming better characterized at the genome-wide level, further work is necessary to understand their role in nuclear processes, such as gene regulation (19).
Mapping of DNA methylation, histone modifications and noncoding RNAs simultaneously in the same cell types will allow scientists to begin to better understand the cross-talk that occurs among these epigenetic regulatory mechanisms. Epigenomic data sets also have remarkable power to identify functional chromosomal regions (19).

Given the complexity involved in cellular regulation, epigenome maps will undoubtedly reveal new principles in the regulation of genome structure and function (19). Epigenetic changes are inherently more plastic and dynamic than genetic changes and thus may be particularly useful targets for therapeutic intervention (20).

Epigenetics in its classic definition describes mitotically heritable modifications of DNA or chromatin that do not alter the primary nucleotide sequence $(21,22)$. A wider definition that is still consistent with the literal meaning ('epi'; Greek for 'on top of' or 'in addition to') would include stable yet reversible molecular mechanisms that lead to a given phenotype without a change in genotype. Epigenetic states can be mitotically inherited and thereby provide a mechanism for the long-term maintenance of cellular identity. Despite their stability, however, epigenetic marks can be readily reprogrammed experimentally using various strategies, including nuclear transfer, cell fusion and ectopic expression of transcription factors.

Some of the interest can be explained by the opportunity to generate large numbers of customized iPS cells for regenerative medicine, disease modeling and other applications (23). From a basic research perspective, pluripotent stem cells provide a powerful model to study the interplay of epigenetic modifications and dynamics during cellular differentiation (24).

\section{Epigenetic Regulation}

In order to fully understand the complexity of epigenetic regulation and the role of these processes in normal stem/ progenitor cell differentiation, we must first begin with an understanding of the tools that a cell uses to control the chromatin structure and how DNA is packaged for function - this packaging constitutes the groundwork of epigenetics. Within a cell, DNA is packaged into chromatin by wrapping $147 \mathrm{bp}$ of DNA around nucleosome complexes composed of pairs of four different histone proteins: $\mathrm{H} 2 \mathrm{~A}, \mathrm{H} 2 \mathrm{~B}, \mathrm{H} 3$, and $\mathrm{H} 4$. The resulting octamer and its surrounding DNA, or the nucleosome, is the fundamental unit of chromatin and plays a key role in 
gene expression. Chromatin can be divided into two main subtypes: first there is euchromatin; in which nucleosomes are more variably spaced and linearly arranged, and which is more permissive for gene transcription. The second chromatin subtype is heterochromatin; which is densely packed in terms of both nucleosome spacing along the DNA and higher or- dearrangement of the nucleosomes, and thus restricted for the access of transcription factors, facilitating transcriptional repression and gene silencing $(25,26)$.

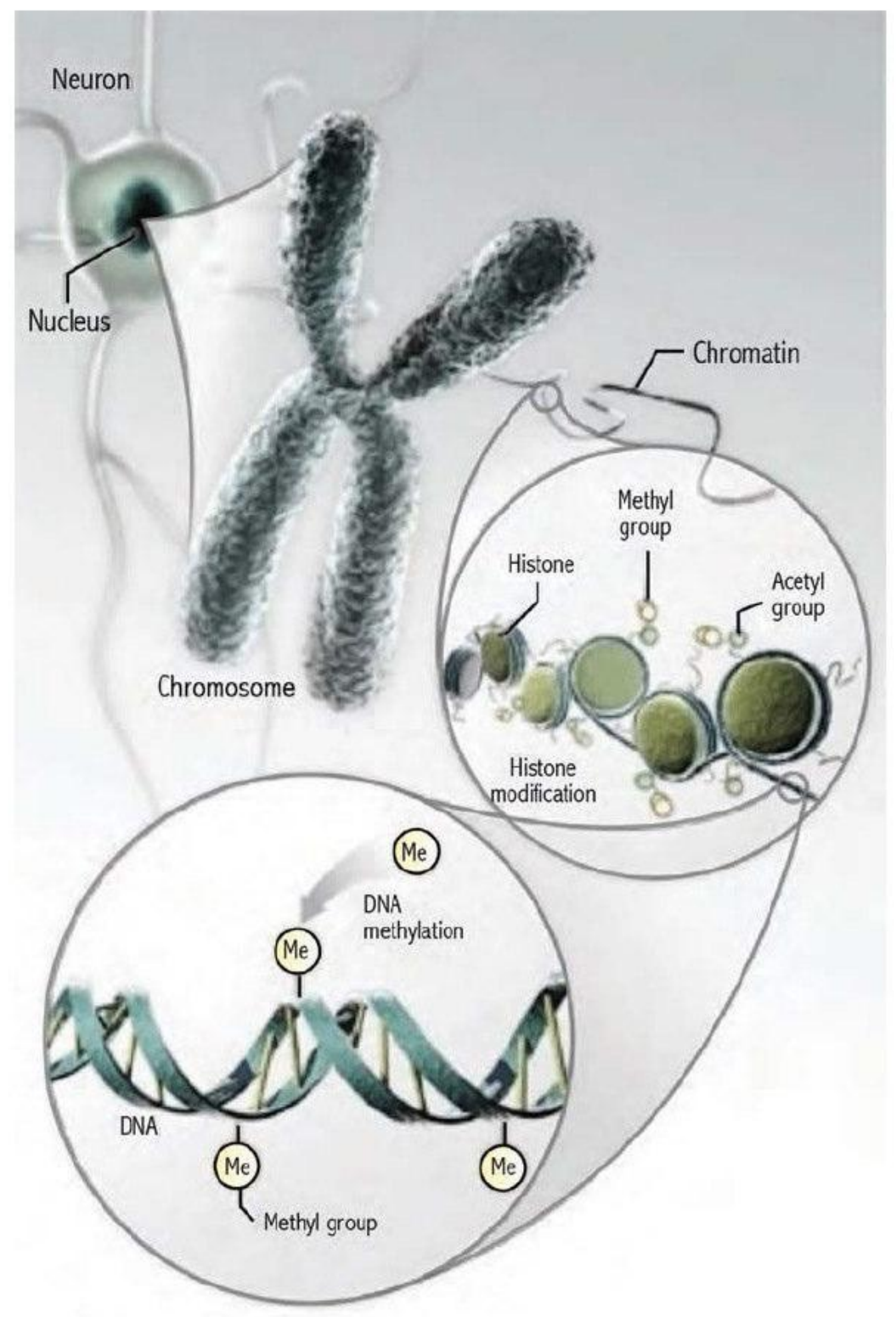

Figure 1. Histone acetylation tends to promote gene activity, whereas histone methylation and DNA methylation tend inhibit it (Adapted with permission from Meany M et al, American Association for the Advancement of Science, 2010). 
DNA methylation, along with histone modification (acetylation, methylation, phosphorylation, ubiquitination, etc.) and miRNA regulation are considered to be mechanisms of epigenetic regulation. Epigenetic modulation changes the expression of a gene without making any changes to the DNA. Such epigenetic differences allow two cells within the same organism that contain the same genetic complement of DNA to express a unique subset of genes and to differentiate (27).

For didactic purposes, epigenetic modifications can be grouped into three main categories: DNA methylation, histone modifications and nucleosome positioning. It is important to keep in mind the interplay between epigenetic factors - as the observed outcome is always the sum of their interactions - and the many positive and negative feedback mechanisms (28).

\section{DNA Methylation}

The most widely studied epigenetic modification in humans is cytosine methylation. DNA methylation occurs almost exclusively in the context of $\mathrm{CpG}$ dinucleotides. The $\mathrm{CpG}$ dinucleotides tend to cluster in regions called CpG islands (29), defined as regions of more than 200 bases with a $\mathrm{G}+\mathrm{C}$ content of at least $50 \%$ and a ratio of observed to statistically expected $\mathrm{CpG}$ frequencies of at least 0.6 . CpG dinucleotides are usually quite rare in mammalian genomes $(\sim 1 \%)$. In general, CpG-island methylation is associated with gene silencing. DNA methylation plays a key role in genomic imprinting, where hypermethylation at one of the two parental alleles leads to monoallelic expression (30). DNA methylation can inhibit gene expression by various mechanisms. Methylated DNA can promote the recruitment of methyl-CpG-binding domain (MBD) proteins. MBD family members in turn recruit histone-modifying and chromatin-remodeling complexes to methylated sites $(31,32)$. DNA methylation can also directly inhibit transcription by precluding the recruitment of DNA binding proteins from their target sites (33).

\section{Histone modifications}

Histones are key players in epigenetics. The core histones $\mathrm{H} 2 \mathrm{~A}, \mathrm{H} 2 \mathrm{~B}, \mathrm{H} 3$ and $\mathrm{H} 4$ group into two H2.A-H2.B dimers and one $\mathrm{H} 3-\mathrm{H} 4$ tetramer to form the nucleosome. The core histones are predominantly globular except for their $\mathrm{N}$-terminal tails, which are unstructured (34). Histone $\mathrm{H} 1$ is called the linker histone. It does not form part of the nucleosome but binds to the linker DNA (that is, the DNA separating two histone complexes), sealing off the nucleosome at the location where DNA enters and leaves (35). All histones are subject to post-transcriptional modification. Several post-transcriptional modifications occur in histone tails: acetylation, methylation, phosphorylation, ubiquitination, SUMOylation and ADP ribosylation $(34,36)$, among others. Histone modifications have important roles in transcriptional regulation, DNA repair (37), DNA replication, alternative splicing (38) and chromosome condensation (34).

\section{Nucleosome positioning}

Nucleosomes are a barrier to transcription that blocks access of activators and transcription factors to their sites on DNA, at the same time they inhibit the elongation of the transcripts by engaged polymerases. The packaging of DNA into nucleosomes appears to affect all stages of transcription, thereby regulating gene expression (28). Nucleosome positioning not only determines accessibility of the transcription factors to their target DNA sequence but has also been reported to play an important role in shaping

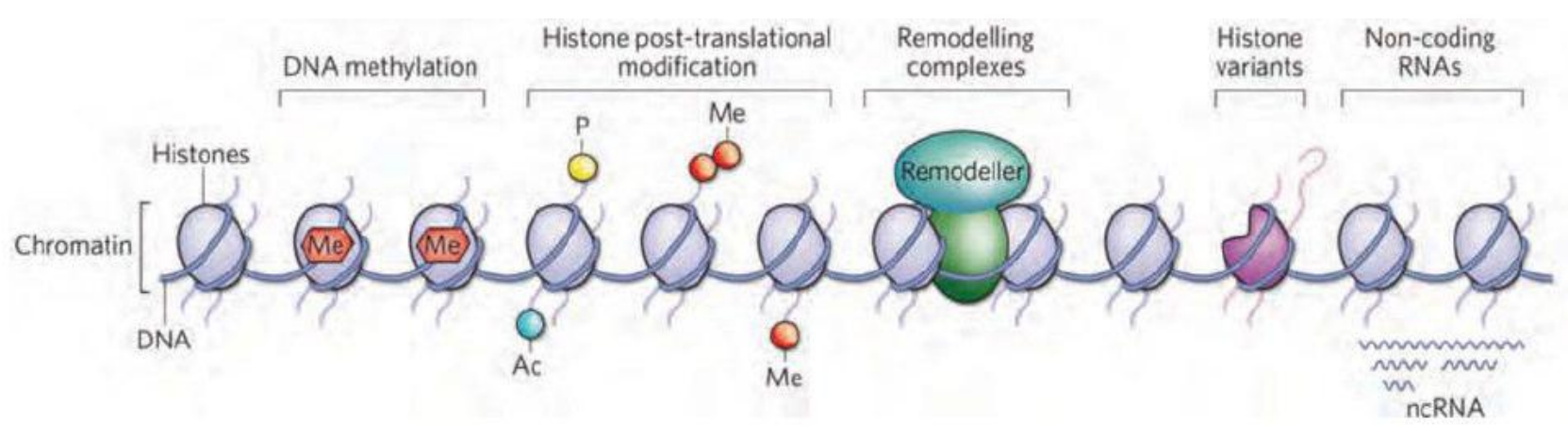

Figure 1. Mechanisms involved in chromatin modifications (Adapted with permission from Dulac C, Nature Publishing Group, 2010). 
the methylation landscape (39). Besides transcription regulation, nucleosome occupancy also participates in directing meiotic recombination events (40).

Epigenetic changes are defined as alterations in gene expression that are self-perpetuating in the absence of the original signal that caused them $(41,42)$. A major class of epigenetic mechanism is thought to involve persistent changes in chromatin structure (Fig. 2). Most, if not all, transcriptional regulatory events cause changes to chromatin structure and composition, which result from the recruitment of chromatin-modifying enzymes by transcription factors and by the transcriptional machinery itself. Less is known about whether, or under which circumstances, chromatin modifications can be stably maintained or propagated.

\section{Plasticity and Epigenetic Modification}

Plasticity refers to the capacity of organisms or cells to alter their phenotype in response to changes in their environment. This property can be studied at the level of the genome (by analyzing epigenetic modifications), the individual cell, and the organism (during development of the embryo or changes in behavior in adults, for example). In contrast to previously held views, recent studies show that cells are remarkably plastic. Revealing the molecular and cellular mechanisms that underlie this plasticity is a dynamic area of biology and one that holds great promise for developing new therapies (43).

During early mammalian development as the pluripotent cells that give rise to all of the tissues of the body proliferate and expand in number, they pass through transition states marked by a stepwise restriction in developmental potential and by changes in the expression of key regulatory genes. Recent findings show that cultured stem cell lines derived from different stages of mouse development can mimic these transition states. They further reveal that there is a high degree of heterogeneity and plasticity in pluripotent populations in vitro and that these properties are modulated by extrinsic signaling (44).

Pluripotent stem cells have two remarkable properties: immortality, or the capacity for indefinite self-renewal; and pluripotency, the ability to give rise to all the tissues of the adult body. The derivation of pluripotent stem cells from the human embryo $(45,46)$ (human embryonic stem (ES) cells) and the development of pluripotent stem cells (induced pluripotent stem (iPS) cells) through the reprogramming (47) of adult human cells $(2,4)$ are seminal technological breakthroughs that hold the promise of revolutionizing biomedical research. Studies of the molecular basis, be it genetic or epigenetic, of these natural and induced pluripotent states, as well as investigations into how pluripotency is maintained and the mechanisms of lineage commitment, are important not only for improving the understanding of mammalian embryogenesis and cellular differentiation but also for developing successful stem-cell-based therapies for regenerative medicine.

An emerging view of the stem-cell state holds that it is not an invariant and cell-autonomous state but, instead, should be considered as the dynamic response of the cell lineage as a whole to the external environment (48). The inner cell mass and epiblast of the mouse embryo, and presumably their human counterparts, are dynamic cell populations whose interactions with the extra-embryonic tissues surrounding them are crucial for cell-fate determination $(49,50,51)$. These interactions evolve rapidly as the developmental program unfolds, and the response of the pluripotent cells to external signals changes swiftly within a short time frame. This dynamism is reflected in the plasticity of pluripotent stem cell populations in vitro in response to manipulations of the cell-culture environment.

Heterogeneity and plasticity are both features of in pluripotent stem-cell populations that could be exploited to aid in the propagation and directed differentiation of cells in vitro, as well as in refining strategies for cell reprogramming (44).

An attractive candidate for the molecular mechanism underlying plasticity is epigenetic modifications. Persistent changes in chromatin structure are thought to contribute to mechanisms of epigenetic inheritance. Five broad and interrelated mechanisms are known to affect chromatin structure: DNA methylation, histone modification, remodeling by chromatin-remodeling complexes, insertion of histone variants, and the effects of non-coding RNAs (ncRNAs). All five have been shown to be essential contributors to the development and cellfate determination of tissues. Chromatin modifications occurring at different time points during the life of an organism have been associated with various short-to longlasting regulatory events that affect the development and the function of the brain and other tissues (52). 
Epigenetic Modification in Pluripotent and Differentiated Cells

In recent years, great strides have been made in our understanding of the biology of human ES cells and their ability to differentiate into multiple lineages. Although it has always been obvious that the differentiation of stem cells does not come about due to changes to the primary sequence of the genome, only now are we beginning to understand the mechanisms involved in this process. Chromatin modification has been shown to control the expression of key genes involved in the progression of stem cells into their differentiated progeny (27).

Chromatin remodeling is an epigenetic phenomenon that affects gene transcription within a cell and, thereby, its phenotype. Since differentiation of ES cells is accomplished by changing the epigenomic profile of the cell, it is reasonable to assume that reversing the process will allow us to effectively derive pluripotent cells from differentiated cells. It is therefore critical to understand the various processes involved in maintaining and changing the epigenomic profile of cells (27).

Specific epigenetic features underpin the pluripotency of ES cells. Recent studies have demonstrated that ES cell chromatin is in a highly dynamic state with an apparently transient association of chromatin structural proteins, which is reflected in the relatively decondensed chromatin of ES cells (53). This dynamic exchange of chromatin proteins, including histones within intact chromatin in ES cells, is not a function of replication, but rather a potentially ES-unique mechanism whereby histone modifications might be dynamically deposited on and off the chromatin at development control genes. Moreover, there is a general abundance of transcriptionally active chromatin marks such as trimethylation of lysine 4 of histone $\mathrm{H} 3$ (H3K4me3) and acetylation of histone $\mathrm{H} 4$ (H4Ac) (54).

Genes encoding regulators of early development are associated with bivalent chromatin domains $(54,55)$. These regions have the repressive mark of trimethylation of lysine 27 on histone $\mathrm{H} 3(\mathrm{H} 3 \mathrm{~K} 27 \mathrm{me} 3)$ as well as the $\mathrm{H} 3 \mathrm{~K} 4 \mathrm{me} 3$ mark that is associated with active genes. The presence of these opposing marks suggests that these genes are poised to be released from repression as soon as ES cells will be induced to differentiate. Interestingly, many of the regions that are bivalently marked are also bound by the key transcription factors associated with pluripotency; Oct-3/4, Nanog and Sox2 (56).
Epigenetic modifications constitute a complex regulatory layer on top of the genome sequence. Pluripotent and differentiated cells provide a powerful system for investigating how the epigenetic code influences cellular fate. High-throughput sequencing of these cell types has yielded DNA methylation maps at single-nucleotide resolution and many genome-wide chromatin maps. In parallel to epigenome mapping efforts, remarkable progress has been made in our ability to manipulate cell states; ectopic expression of transcription factors has been shown to override developmentally established epigenetic marks and to enable routine generation of induced pluripotent stem (iPS) cells (24).

\section{The epigenetic landscape in ES cells}

Whereas genetic knockout and biochemical studies have shed light on the functions of particular DNA and histone modifications, genome-scale studies have provided a broader picture of the functional relevance and roles of epigenetic marks. Recent technological advances have led to comprehensive maps of DNA methylation in mouse and human pluripotent cells (57-59). Similar to the extensive catalog of DNA methylation maps, dozens of chromatin state maps from mouse and human pluripotent cells have been published. Globally, ES cells show an open chromatin structure, and active chromatin domains are widespread (61-66). The open ES cell chromatin structure, which is enriched in non-compact euchromatin, allows easy access for transcription factors and the transcriptional machinery and may explain observed global 'hyper-transcription'. By contrast, lineage commitment is accompanied by the accumulation of regions of highly condensed, transcriptionally inactive heterochromatin (67).

\section{Dynamic epigenetic changes during differentiation}

Despite significant advances in mapping technologies, it is still difficult to investigate lineage specification and the associated global epigenetic remodeling for many cell types in vivo. But the number of cells that is required for epigenetic analysis continues to decrease, suggesting that these exciting studies will become possible in the near future $(68,69)$. In the meantime, ES cells provide a powerful in vitro system to study the role and extent of epigenetic modification during lineage commitment.

\section{Epigenetic modifications in ES cells.}

Both undifferentiated and differentiated ES cells are widely used to study epigenetic mechanisms - the former because they express many epigenetic modifiers and the latter because they serve as a model of dynamic chromatin 
remodeling. Functional studies have shown that most epigenetic marks, including DNA methylation, are not required for the survival of pluripotency marker-positive cells in culture. Although if ES cells lacking epigenetic marks can be maintained, they cannot properly execute their developmental potential.

In summary, DNA methylation and histone modifications seem to have distinct targets and roles in undifferentiated ES cells. Because of their largely nonoverlapping functions, it may be possible to delete any one modification without completely disrupting the undifferentiated state. It will be important to use double and higher-order knockouts to dissect such compensatory effects.More dynamic and genome-scale data on epigenetic changes during differentiation will certainly advance our understanding of the respective roles of these epigenetic modifications (24).

\section{Cell Signaling and} the Epigenetic Machinary

The genomic distributions of the three main modulators of the epigenome (28)-DNA methylation, histone modifications and nucleosome positioning - are rapidly being elucidated across the genomes of multiple cell types using a growing series of sequencing-and microarraybased technology $(19,70)$.

Epigenetic processes will thereby regulate the balance between stem, progenitor and mature cells in adult and developing tissues as well as fostering abnormal cell population states, such as in cancer (71). As we obtain knowledge of the above genomic patterns, we are challenged to understand what cellular signaling processes dictate their development and how they contribute to cellular differentiation. One way to envision dissecting this is to consider the Waddington landscape model, as recently interpreted by several authors (7276). Waddington envisioned development starting with a marble at the top of a hill and initially having the totipotent state of a zygote cell (Fig. 3). As the totipotent zygotic cell rolls down the hill, it-with some degree of stochasticity-enters a series of furrows that induce increasingly restrictive, more committed cell fates as the totipotent cell changes to a multipotent adult stem cell and then to differentiated cells of adult tissues. This trip through the valleys is further associated with the evolving patterns of epigenetic states that maintain the cell fate changes key to each developmental and differentiation stage (73).

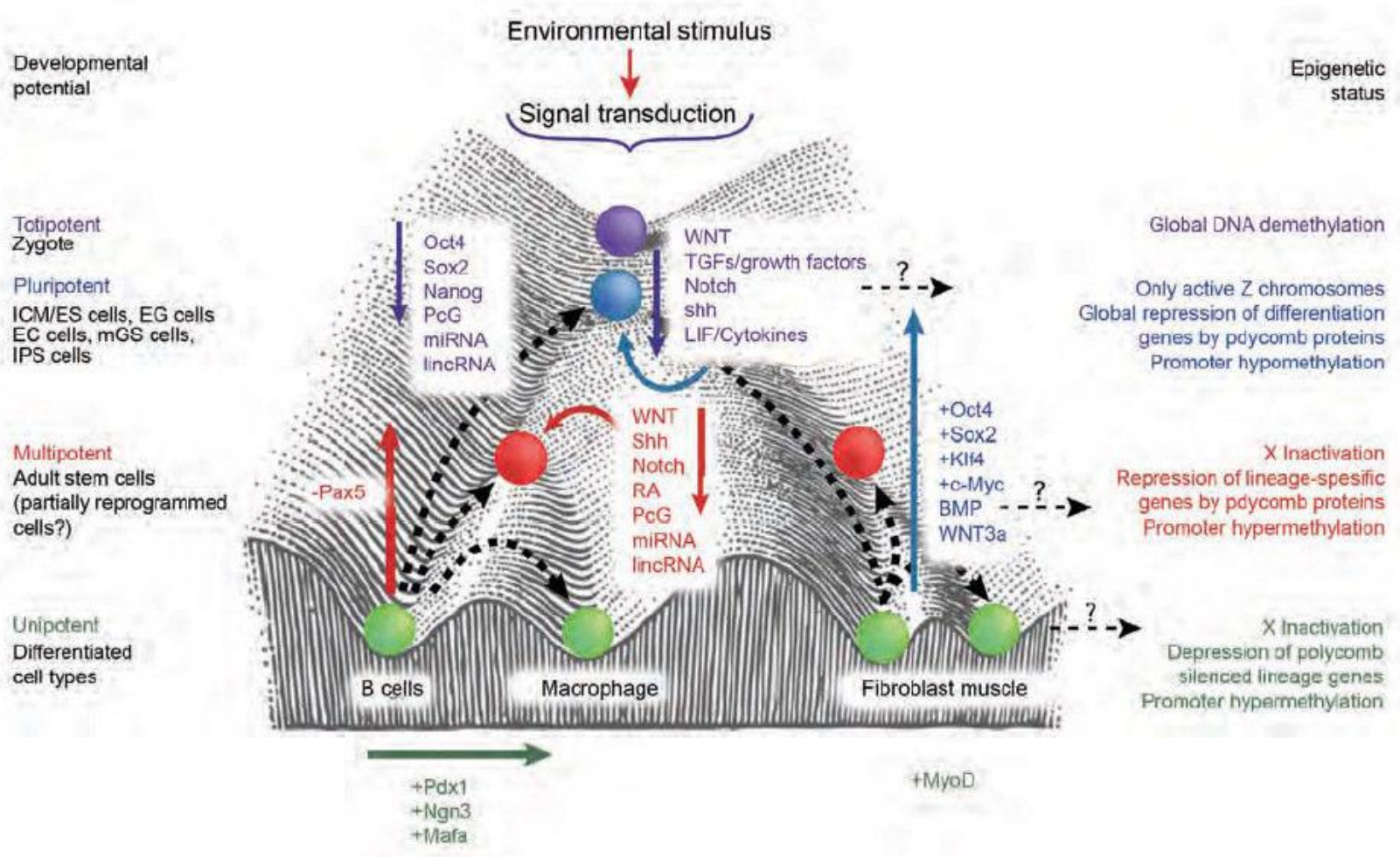

Figure 3. Depiction of potential cell signaling in Waddington's model of epigenetic determination of development, as interpreted by Hochedlinger and Plath (Adapted with permission from Mohammad HP, et al. Nature Publishing Group 2010). 
During cellular reprogramming to an induced pluripotent state (iPS cells), the marble is pushed progressively back 'uphill' in a process that must reverse many of the mature epigenomic modifications (71).

Studies of the mechanisms of iPS cell generation have further clarified the need for orchestration of the epigenetic landscape in early development. The critical step during dedifferentiation to iPS cells is the activation of transcription factors that maintain the embryonic state and the downregulation of factors promoting cell differentiation, whereas epigenetic silencing of pluripotency genes, such as OCT4 and NANOG, is associated with the onset of lineage commitment (75). The silencing of these genes appears to be a molecular progression. The presence of repressive histone modifications emerges first to dictate transcriptional silencing. This is then locked in by the imposition of DNA methylation (76-79) which further prevents reprogramming to the undifferentiated state (7678 ). Studies of iPS cell generation have identified potential roles for the enzyme cytidine deaminase (AID) and the Tet family of proteins as DNA demethylases for the pluripotency genes in the final steps of converting committed cells back to ES Cell-like cells $(80,81)$.

As genes in ES Cells undergo changes in their epigenetic status, transcription factors regulate downstream target genes that are critical to the epigenetic landscapes that evolve during development. OCT4, SOX2 and NANOG are part of a regulatory network that includes their own promoters and promoters of genes that are targets of the polycomb-group (PcG) protein complexes that mediate long-term gene silencing $(82,83)$.

The Wnt pathway that is involved at all of these stages. In terms of supporting pluripotency, the ligand Wnt $3 \mathrm{a}$ can replace overexpression of the nuclear oncogene product, c-Myc, a key downstream target of Wnt pathway signaling, in potentiating the generation of iPS cell (Fig. 3) (84). Growth factors are a second major group of signaling molecules to be considered. This class of morphogens, critical for appropriate development, includes bone morphogenetic proteins, transforming growth factors (TGFs) and fibroblast growth factors (FGFs). Specifically, FGFs and TGFs have been shown to sustain expression, by means of downstream signaling to Smad proteins, of the pluripotency factors Oct4, Sox 2 and Nanog that promote the undifferentiated potential of human ES Cells (85). Growth factor withdrawal has been exploited to push ES Cells toward differentiation, thus allowing inferences with respect to the influence of growth factor signaling on epigenetic alterations during differentiation $(86,87)$.

The cytokine leukemia inhibitory factor (LIF) has been associated with supporting the undifferentiated state of mouse ESCs. LIF confers its signal to a cascade that results in activation of STAT3, expression of which has been shown to be important in retention of the pluripotent state of ESCs $(88,89)$.

The above examples are pathways that maintain stemness of ES Cells, signaling cascades are also critical to the commitment of these cells during development and maintenance of the progenitors for various cell lineages that emerge in development. For example, activation of the Wnt pathway is important for the differentiation of neuronal precursors and the specification of the forebrain in vivo $(90,91)$. Disruption in the downstream mediator of Wnt, $\beta$-catenin, results in decreased proliferation of neural progenitors and defects in neuronal migration $(92,93)$.

Retinoic acid signaling is also essential for neural development and involved in specification, differentiation and outgrowth of axons (94). Additionally, retinoic acid can induce differentiation of human and mouse ES Cells, and embryonic carcinoma (EC) cells (95). Similarly, Notch signaling appears critical for key stages of development.

Finally, Sonic Hedghog (Shh) signaling is critical for the development of many organs including the brain, the lung and endocrine system. It promotes the appropriate differentiation of ES Cells (96), but has also been implicated in self-renewal of normal stem cells.

The imposition of epigenetic states establishes heritable activation and repression of gene transcription through a host of activating or repressing histone modifications, in some cases coupled to DNA methylation and changes in nucleosome positioning (97). All of these steps involve a battery of enzymes and protein complexes, including histone methyltransferases (HMTs), histone acetyltransferases (HATs), histone deactylases (HDACs), histone demethylases (KDMs), histone deacetylases, DNA methyltransferases (DNMTs), DNA demethylases and nucleosome remodeling complexes (98). The activity of all of these proteins could be regulated by signaling molecules.

From the standpoint of Waddington's model in Figure 3 , we might surmise that any environmental signaling for control of ES Cells might influence the balance between stemness retention and commitment. Central to this would be the regulation of embryonic transcription factors, such as OCT4, SOX2 and NANOG. Might then the epigenetic control of embryonic transcription factors be influenced by pathways such as Wnt, bone morphogenetic proteins, TGFs, FGFs or cytokines, such as LIF?

One pathway linked to such control is Shh, which increases progenitor cell number in a manner dependent upon the PcG factor, Bmil. Bmil is a component of the $\mathrm{PcG}$ complex that recognizes the repressive histone mark H3K27me3. 
Notch is another pathway that is increasingly implicated in the control of the epigenetic landscape. As mentioned earlier, a recent study describes a new role for the histone demethylase, KDM5A, as playing an integral function in a Notch repressor complex. This PcG interacting histone demethylase $(99,100)$, which would decrease the key transcriptional activating mark, H3K4me3, associates with the Notch nuclear effector protein, RBP-J, in a manner essential for Notch/RBP-J target gene silencing (101).

The control of the balance between ES Cell stemness and commitment also appears to involve miRNAs and other non-coding RNAs. Specifically, a family of c-Mycregulated miRNAs regulates the expression of pluripotency and differentiation factors $(102,103)$.

Signaling may thus involve regulation of the expression status of non-canonical, noncoding RNAs, adding an additional layer of complexity by which signaling can alter cell states to ultimately promote heritable alterations to the epigenome.

The environment for cell renewal-the 'stem cell niche'-might be imagined as the furrows (those at the very bottom of the model) for interaction with stem and progenitor cells in the Waddington model (104). Stem cell niches provide special microenvironments for adult stem cells. The signaling factors in the niche are thought to regulate the epigenetic mechanisms responsible for maintaining the balance between adult stem cell selfrenewal and lineage commitment.

\section{Epigenetic Reprogramming and Induced Pluripotency}

Under certain experimental conditions, differentiated cells can revert into a less differentiated state, a process termed 'nuclear reprogramming'. Examples include the generation of pluripotent ES cells from unipotent B lymphocytes or neurons by somatic cell nuclear transfer (SCNT) (105107), or the derivation of pluripotent embryonic germ (EG) cells from unipotent primordial germ cells (PGCs) upon cell explantation $(108,109)$. Reprogramming also describes the conversion of one differentiated cell type into another, for instance of a B lymphocyte into a macrophage (110), or a fibroblast into a muscle cell (111), following the expression of a single transcription factor.

The term nuclear reprogramming is used to describe either functional or molecular changes to cells undergoing fate changes. When used as a functional term, reprogramming describes experimentally induced, stable changes in cell fate. It is most often used in the context of the reprogramming of adult cells into pluripotent cells, which can be achieved in various ways; for example, by SCNT, by the fusion of somatic cells with pluripotent cells, by explanting germline cells, or by the expression of a defined set of transcription factors in somatic cells (112). Functional reprogramming also includes the stable conversion of one differentiated cell type into another by transcription factors; for example, the conversion of $\mathrm{B}$ cells into macrophages, fibroblasts into muscle cells or pancreatic acinar cells into $\beta$ cells. The terms 'transdifferentiation' and 'lineage conversion' are used to describe this latter type of reprogramming because it is unclear if it involves the de-differentiation of cells into a less-differentiated progenitor cell, as it occurs during the reprogramming of adult cells into pluripotent cells. When used as a molecular term, reprogramming describes the molecular changes that cells undergo as their fate changes. For example, during the epigenetic reprogramming of cells, the promoter regions of pluripotency genes undergo demethylation following either SCNT or induced pluripotency. Epigenetic reprogramming has also been used to describe certain molecular changes that occur during development, irrespective of changes to the differentiation state of cells, such as the DNA and histone methylation changes that occur during germ cell maturation (73).

Kazutoshi Takahashi and Shinya Yamanaka extended the observations that ES cells contain dominant reprogramming activity and that transcription factors are potent inducers of cell fate changes by identifying four transcription factors, Oct4, Sox2, Klf4 and cMyc, from 24 predominantly ES cell-specific genes, that were sufficient to reprogram adult mouse cells (fibroblasts) into ES-like iPS cells when expressed retrovirally (2).

At the molecular level, completely reprogrammed iPS cells show transcriptional patterns that are highly similar to those in ES cells, as well as DNA demethylation of the promoter regions of Oct4 and Nanog and, in female cells, the reactivation of the somatically silent $\mathrm{X}$ chromosome. Moreover, iPS cells exhibit global patterns of histone methylation, including histones H3 lysine 4 (K4) and lysine 27 (K27) trimethylation, that are virtually indistinguishable from those in ES cells (113-116). At the functional level, completely reprogrammed iPS cells produce viable chimeric mice and contribute to the germline, and even support the development of embryos that are derived entirely from iPS cells (116-118). 


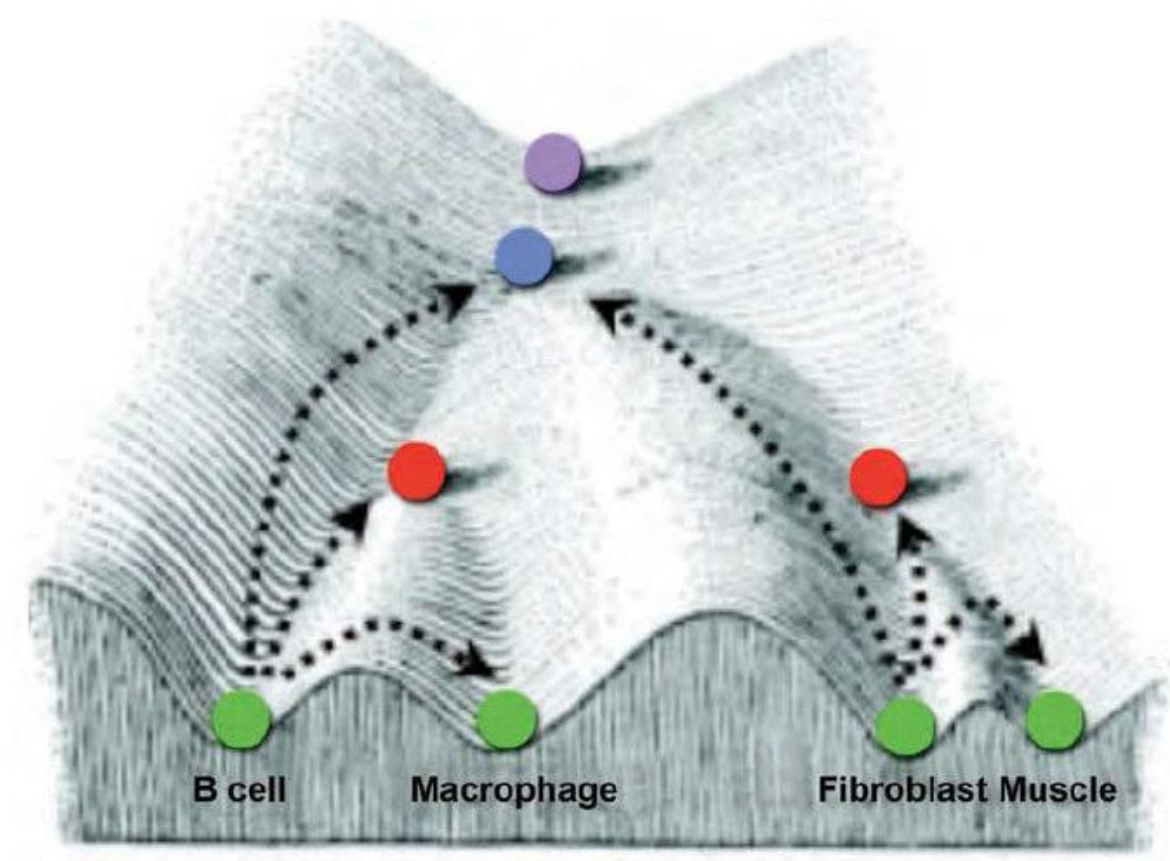

Figure 4. Nuclear Reprogramming (Adapted with permission from Hochedlinger K, et al, The Company of Biologist Ltd. 2009).

Three approaches to nuclear reprogramming to pluripotency are:

\section{(a) Nuclear transfer}

In this approach, the nucleus of a somatic cell (which is diploid, $2 n$ ) is transplanted into an enucleated oocyte. In the environment of the oocyte, the somatic cell nucleus is reprogrammed so that the cells derived from it are pluripotent. From this oocyte, a blastocyst is generated, from which ES-cell lines are derived in tissue culture. If development is allowed to proceed to completion, an entire cloned organism is generated.

(b) Cell fusion

In this approach, two distinct cell types are combined to form a single entity. The resultant fused cells can be heterokaryons or hybrids. If the fused cells proliferate, they will become hybrids, and on division, the nuclei fuse to become $4 n$ (that is, twice the number of chromosomes in a somatic cell) or greater. If the cells are derived from the same species, their karyotype will remain euploid (that is, they will have balanced sets of chromosomes); however, if they are from different species, they will be aneuploid, as chromosomes will be lost and rearranged.

\section{(c) Transcription factor transduction}

This approach can be used to form iPS cells, which have similar properties to ES cells and can be generated from almost any cell type in the body through the introduction of four genes (Oct4, Sox2, Klf4 and $c-M y c)$ by using retroviruses. The pluripotent state is heritably maintained, and vast numbers of cells can be generated, making this approach advantageous for clinical applications (75).

An open question is how the reprogramming factors induce the epigenetic changes that are associated with reprogramming to pluripotency. The fact that KLF4 and cMYC can be replaced by NANOG and by the RNAbinding protein LIN28 in human fibroblast reprogramming experiments suggests that different molecular pathways can lead to reprogramming or, alternatively, that these factors perform highly similar functions during this process. In support of the latter, LIN28 was recently found to function as a negative regulator of microRNA processing in ES cells, specifically of members of the let-7 family (119). cMYC represses the transcription of similar miRNAs, suggesting that LIN28 and cMYC could perturb the same regulatory mechanisms that contribute to reprogramming (120).

The effect of cMyc can be partially compensated by treating cells with either the histone deacetylase (HDAC) inhibitor valproic acid (VPA) or a ligand of the $\beta$-catenin pathway, Wnt3a $(84,121)$. Moreover, VPA can replace the function of both $\mathrm{CMYC}$ and KLF4 in human cell reprogramming, such that only the expression of OCT4 and SOX2 are required to generate iPS cells (122). 
Reprogramming needs to inactivate the somatic cell program and to activate the ES cell-specific transcription programs of self-renewal and pluripotency. One could speculate that the reprogramming factors contribute to both functions, as they can, in ES cells, be both repressive and activating. Thus, genes that encode somatic cell regulators could be repressed by the binding of the reprogramming factors, while self-renewal and pluripotency genes would be turned on. Autoregulatory loops, i.e. the binding of factors to their own promoters (123), could provide a platform on which ectopic transcription factors can jump-start the transcription of their endogenous counterparts to a level that is sufficient to maintain their own expression. Furthermore, the ectopic activation of lineage differentiation programs that has been observed in partially reprogrammed cells might reflect a function of Klf4 and Sox 2 in normal development (114).

The reprogramming factors can also have more global functions that do not involve direct transcriptional control, which remain completely unexplored. A few pleiotropic functions have been suggested for $\mathrm{cMyc}$, ranging from control of initiation of DNA replication (124) to global effects on chromatin structure, especially on histone acetylation (125), which could be important for providing the other reprogramming factors access to target sites.

Thus, reprogramming is likely to be more complex than a simple model suggests, and will involve a number of different mechanisms to overcome the epigenetic barriers that are imposed during differentiation.

\section{Induced Pluripotent Stem Celss (iPS Cells)}

The advent of SCNT (1) opened up the possibility to reprogram somatic cells to produce patient-specific pluripotent and conditionally immortalized ES-like cells, potentially useful in manufacturing novel cell-based therapies $(126,127)$.

In order to elucidate the vital role of the ES cell epigenome, including the pluripotency-specific DNA methylation pattern, it is noteworthy to review the recent advances in study- ing the molecular transcriptional networks that maintain ES cell identity. Oct-3/4, Nanog and Sox 2 transcription factors have been identified as crucial regulators of pluripotency (56).

The Oct- $3 / 4$ gene is a member of the POU family of transcription factors; it is expressed in ES cells and in embryonic carcinoma (EC) cells $(128,129)$. Oct- $3 / 4$ is essential for the pluripotent identity of the founder cell population in the ICM (130). Furthermore, it was shown that a critical amount of Oct-3/4 is required to sustain stem cell self-renewal, and any up- or down-regulation induces divergent developmental programs (131). Nanog is an NK-2 class homeobox transcription factor that is expressed throughout the pluripotent cells of the ICM but is down-regulated in extraembryonic lineages and in pluripotent cells of the peri-implantation embryo (132). Forced expression of Nanog, unlike that of Oct-3/4, is sufficient to maintain the pluripotent state in mouse ES cells in the absence of LIF (leukemia inhibitory factor) $(132,133)$, and in human ES cells results in cells that can be propagated in the absence of feeder cells and associated signaling (134). Nanog-null embryos fail to maintain the pluripotent lineage and arrest at periimplantation. The third transcription factor, Sox2, is a member of high mobility group (HMG) protein family that is expressed in the ICM, early primitive ectoderm, anterior primitive ectoderm, germ cells, and multipotent extra embryonic ectoderm cells $(135,137)$. Although Sox 2 expression is not restricted to pluripotent cells it plays an important role in the maintenance of pluripotency and lineage specification. These three transcription factors, which determine early cell fate decisions and regulate ES cell pluripotency, bind to their own promoters to form an interconnected selforganizing network (123).

The growing understanding of the transcriptional regulation in ES cells has led to the discovery of the factors that terminally can turn differentiated cells into ES celllike cells. Co-introduction of four transgenes encoding the transcription factors Oct-3/4, Sox2, c-Myc, and Klf4 into somatic cells, such as embryonic and adult tail-tip fibroblasts, resulted in the generation of iPS cells, which gave rise to chimeric embryos following their injection into mouse blastocysts (Fig 5) (47).

Both Klf4 and c-Myc are oncogenes $(137,138)$, which play a role in reducing ES differentiation (139) and promoting ES self-renewal (140), respectively. It is thought that these four factors establish pluripotency in somatic cells as follows. First, c-Myc promotes DNA replication, thus re- laxing the chromatin structure, which in turn allows Oct-3/4 to access its target genes. Sox 2 and Klf4 also co-operate with Oct-3/4 to activate target genes that encode transcription factors that establish the pluripotent transcription factor network (such as Nanog). Interestingly, these transcription factors activate epigenetic regulators, including several histone demethylases that were shown to be positively regulated by Oct-3/4 (141), and that are involved in establishing the pluripotent epigenome. The induction of pluripotency was recently 


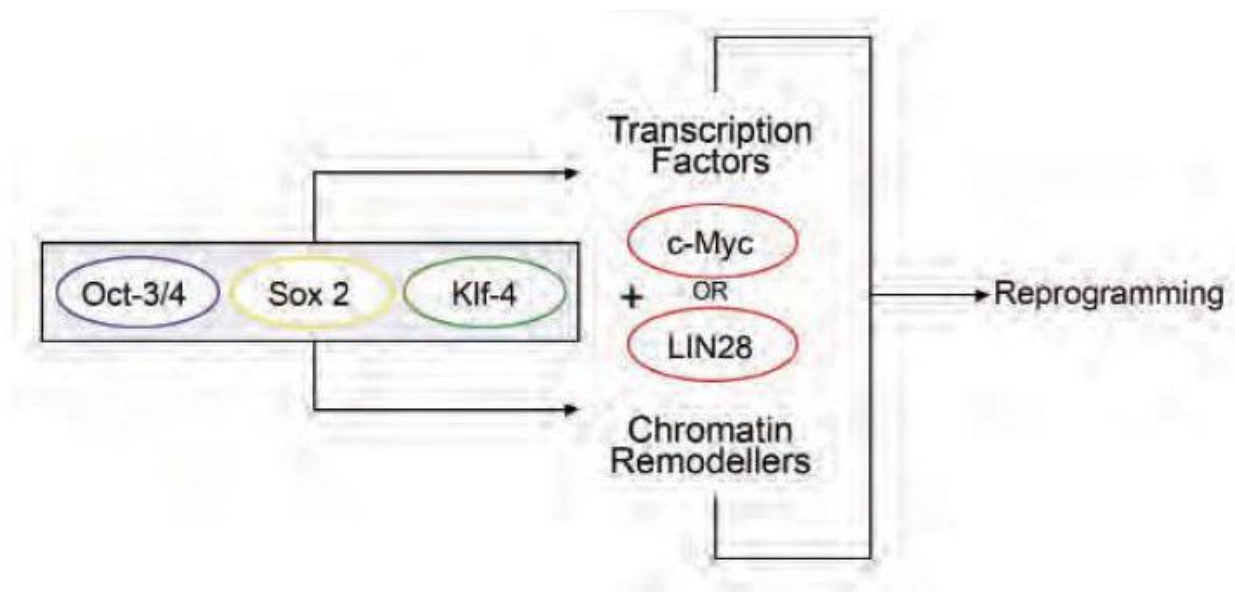

Figure 5. Transcriptional networks that control reprogramming (Adapted with permission from Abu. Remaileh et al, Humana Press, 2009).

achieved in human cells as well. Human fibroblasts were reprogrammed into human iPS $(2,4)$, using either the same four factors described above, or a new "mix" containing Oct-3/4, Sox 2, K1f4, and LIN28, the latter being an RNAbinding protein that is highly expressed in human ES cells but down-regulated during ES cell differentiation (142).

It is now well established that somatic nuclei can be reprogrammed into a pluripotent state by several experimental manipulations, such as somatic nuclear transfer into oocyte cytoplasm (SCNT) (143), fusion with ES cells (144), and ectopic expression of selected transcription factors (47). The low efficacy of the reprogramming process indicates that epigenetic modification must occur to allow this process to occur.

Clearly, the interaction between the transcriptional network and epigenetic mechanisms are in the heart of generating pluripotent cells. Recent studies described above indeed support the notion that the combination of a set of transcription factors as well as epigenetic regulators (such as Jmjd1a and Jmjd2c histone demethylases (141) are needed for a more complete reprogramming of somatic cells to a pluripotent state. These transcription factors are part of a self-organizing network of transcription factors that prevents differentiation and promote proliferation and pluripotency (145).

iPS reprogramming could subsequently also be achieved with a range of somatic cell types, including differentiated cells such as hepatic (146) or islet $\beta$-cells (147). All of these cells express their own cell-typespecific repertoires of lineage-instructive transcription factors. How does reprogramming proceed in these cases? It seems unlikely that iPS reprogramming factors have evolved to interact with the large variety of lineageaffiliated transcription factors and thus divert regulatory networks within cells that are many branch points away from the pluripotent state. Instead, the low frequency and long duration of iPS reprogramming, in excess of a week $(73,148)$, suggests that stochastic mechanisms are involved and that several rounds of cell divisions are required.

As for directly induced lineage conversions, it is predicted that reprogramming of cells that are developmentally closely related will require fewer transcription factors. Indeed, neural progenitors, which already express Sox 2, Klf4 and Myc, can be turned into iPS cells with only Oct4 (149). However, their reprogramming efficiency remains exceedingly low, suggesting that even here stochastic processes are at play. How reprogramming works remains unclear (148). Oct4 and its partners might gradually gain access to hidden DNA binding sites through the dynamic 'breathing' of chromatin, eventually upregulating the corresponding endogenous factors and thus establishing transgene independence by activating autoregulatory loops. Another mechanism is the direct interaction with chromatin-remodelling proteins, leading to upregulation of critical ES cell regulators such as Nanog (141).

The question then arises whether, given enough knowledge, it will be possible to directly reprogram any cell type into another and to custom-design cells for regenerative therapy from easily obtainable cell sources. Consider cells as an example: we know that transcription factor gain or loss of function can convert these cells into macrophages as well as into T cells and ES cells. But can B cells be induced directly to become, say, haematopoietic stem cells or islet $\beta$-cells at high frequencies, effecting 'long jumps' within the landscape (150).

A promising alternative for the directed induction of desired cell types are in vivo approaches. Perhaps the most spectacular example to date is the conversion of exocrine pancreas cells into fully functional islet $\beta$-cells 
in mice by Pdx1, Ngn3 and MafA $(151,152)$. In spite of these successes, custom-designing cells for cell therapy in humans remain a long way off. Only time will tell whether it will prevail over the application of cells derived from iPS or ES cell lines. But it seems safe to predict that transcription-factor-induced cell reprogramming will continue to reveal hidden secrets of cell differentiation for a long time to come.

\section{Conclusion}

The stable states of differentiated cells are now known to be controlled by dynamic mechanisms that can easily be perturbed. An adult cell can therefore be reprogrammed, altering its pattern of gene expression, and hence its fate, to that typical of another cell type. This has been shown by three distinct experimental approaches to nuclear reprogramming: nuclear transfer, cell fusion and transcription-factor transduction. Using these approaches, nuclei from 'terminally differentiated' somatic cells can be induced to express genes that are typical of embryonic stem cells, which can differentiate to form all of the cell types in the body. This remarkable discovery of cellular plasticity has important medical applications.

\section{References:}

1. Wilmut I, Schnieke AE, McWhir J, Kind A.J, Campbell KH. Nature 1997; 385: 810-3.

2. Takahashi K, Tanabe K, Ohnuki M, Narita M, Ichisaka T, Tomoda $\mathrm{K}$, et al. Induction of pluripotent stem cells from adult human fibroblasts by defined factors. Cell 2007; 131: 861-72.

3. Cibelli J, Kiessling AA, Cunniff K, Richards C, Lanza RP, West MD. Dysfunctional assumptions in bipolar disorder. J Regen Med 2001; 2: 25-31.

4. Yu J, Vodyanik MA, Smuga-Otto K, Antosiewicz-Bourget J, Frane JL, Tian S, et al. Induced pluripotent stem cell lines derived from human somatic cells. Science 2007; 318: 1917-20.

5. Park IH, Zhao R, West JA, Yabuuchi A, Huo H, Ince TA, et al. Reprogramming of human somatic cells to pluripotency with defined factors. Nature 2008; 451: 141-6.

6. Nakagawa M, Koyanagi M, Tanabe K, Takahashi K, Ichisaka T, Aoi T, et al. Generation of induced pluripotent stem cells without Myc from mouse and human fibroblasts. Nature Biotechnol 2008; 26: 101-6.

7. Ohm JE, Baylin SB. Stem Cell Epigenetics. In: Turksen K, editors. Stem Cell Biology and Regenerative Medicine. New York: Humana Press; 2009. P. 235-46.

8. Jakson-Grusby L. DNA Methylation and the Epigenetic Program in Stem Cells. In: Turksen K, editors. Stem Cell Biology and Regenerative Medicine. New York: Humana Press; 2009. P. 277-83.

9. Kangaspeska S, Stride B, Métivier R, Polycarpou-Schwarz
M, Ibberson D, Carmouche RP, et al., Transient cyclical methylation of promoter DNA. Nature 2008; 452: 112-5.

10. Métivier R, Gallais R, Tiffoche C, Le Péron C, Jurkowska $\mathrm{RZ}$, Carmouche RP, et al. Cyclical DNA methylation of a transcriptionally active promoter. Nature 2008; 452: 45-50.

11. Tahiliani M, Koh KP, Shen $\mathrm{Y}$, Pastor WA, Bandukwala $\mathrm{H}$, Brudno $\mathrm{Y}$, et al. Conversion of 5-methylcytosine to 5-hydroxymethylcytosine in mammalian DNA by MLL partner TET1. Science 2009; 324: 930.

12. Bird A. Perceptions of epigenetics. Nature 2007; $447: 396-8$.

13. Suzuki M, Bird A. DNA methylation landscapes: provocative insights from epigenomics. Nat Rev Genet 2008; 9: 465-76.

14. Murrell a, Rakyan VK, Beck $S$. From genome to epigenome, Hum Mol Genet 2005; 14: r3-r10.

15. Ng RK, Gurdon JB. Epigenetic inheritance of cell differentiation status. Cell Cycle 2008; 7: 1173-1177.

16. Zhang TY, Meaney MJ. Epigenetics and the environmental regulation of the genome and its function. Annu Rev Psychol 2010; 61: 439-66.

17. Youngson NA, Whitelaw E. Transgenerational epigenetic effects. Annu Rev Genomics Hum Genet 2008; 9: 233-57.

18. Bernstein BE, Meissner A, Lander ES. The mammalian epigenome. Cell 2007; 128: 669-81.

19. Satterlee JS, Schubeler D, Ng HH. Tackling the epigenome: challenges and opportunities for collaboration. Nat Biotechnol 2010; 28: 1039-44.

20. Haberland M, Montgomery RL, Olson EN. The many roles of histone deacetylases in development and physiology: implications for disease and therapy. Nat Rev Genet. 2009; 10: $285-90$.

21. Bird A. DNA methylation patterns and epigenetic memory. Genes Dev. 2002; 16: 6-21.

22. Jaenisch R, Bird A. Epigenetic regulation of gene expression: how the genome integrates intrinsic and environmental signals. Nat Genet 2003; 33 Suppl: 245-54.

23. Yamanaka S. Strategies and new developments in the generation of patient-specific pluripotent stem cells. Cell Stem Cell 2007; 1: 39-49.

24. Meissner A. Epigenetic modifications in pluripotent and differentiated cells. Nat Biotechnol 2010; 28: 1079-88.

25. Horn PJ, Peterson CL. Molecular biology. Chromatin higher order folding-wrapping up transcription. Science. 2002; 297: 1824-7.

26. Kiefer JC. Epigenetics in development. Dev Dyn. 2007; 236: 1144-56

27. Thyagarajan $B$, Rao M. Role of DNA methylation and epigenetics in stem cells. In: Turksen K, editors. Regulatory Networks in Stem Cells, Stem Cell Biology and Regenerative Medicine. New York: Humana Press; 2009. P. 269-76.

28. Portella A, esteller M. Epigenetic modifications and human disease. Nat Biotechnol 2010; 28: 1056-68.

29. Esteller, M. Epigenetics in evolution and disease. Lancet 2008; 372: S90-S96

30. Kacem S, Feil R. Chromatin mechanisms in genomic imprinting. Mamm. Genome 2009; 20: 544-56.

31. Esteller, M. Epigenetic gene silencing in cancer: the DNA hypermethylome. Hum. Mol. Genet. 2007; 16 Spec No 1: R50-R59

32. Lopez-Serra L, Esteller M. Proteins that bind methylated DNA and human cancer: reading the wrong words. $\mathrm{Br}$. J. Cancer 2008; 98: 1881-5.

33. Kuroda A, Rauch TA, Todorov I, Ku HT, Al-Abdullah IH, Kandeel $\mathrm{F}$, et al. Insulin gene expression is regulated by DNA methylation. PLOS ONE 2009; 4: e6953.

34. Kouzarides T. Chromatin modifications and their function. Cell 2007; 128: 693-705 
35. Daujat S, Zeissler U, waldmann T, Happel N, Schneider R HP1 binds specifi- cally to Lys26-methylated histone $\mathrm{H} 1.4$, whereas simultaneous Ser27 phosphorylation blocks HP1 binding. J. Biol. Chem. 2005; 280: 38090-5.

36. Rando OJ, Chang HY. Genome-wide views of chromatin structure. Annu. Rev. Biochem. 2009; 78: 245-71.

37. Huertas D, Sendra R, Munoz P. Chromatin dynamics coupled to DNA repair. Epigenetics 2009; 4: 31-42.

38. Luco RF, Pan Q, Tominaga K, Blencowe BJ, Pereira-Smith OM, Misteli T. Regulation of alternative splicing by histone modifications. Science 2010; 327: 996-1000.

39. Chodavarapu RK, Feng S, Bernatavichute YV, Chen PY, Stroud $\mathrm{H}, \mathrm{Yu} \mathrm{Y}$, et al. Relationship between nucleosome positioning and DNA methylation. Nature 2010; 466: 388-92.

40. Getun IV, Wu ZK, Khalil AM, Bois PR. Nucleosome occupancy landscape and dynamics at mouse recombination hotspots. EMBO Rep. 2010; 11: 555-60.

41. Berger SL, Kouzarides T, Shiekhattar R, Shilatifard A. An operational definition of epigenetics. Genes Dev 2009; 23 : 781-3.

42. Ptashne M. On the use of the word "epigenetic". Curr Biol 2007; 17: R233-R6.

43. Skipper M, Weiss U, Gray N. Plasticity. Nature 2010; 465: 703.

44. Pera MF, Tam PPL. Extrinsic regulation of pluripotent stem cells. Nature 2010; 465: 713-20.

45. Thomson JA, Itskovitz-Eldor J, Shapiro SS, Waknitz MA, Swiergiel JJ, Marshall VS, et al. Embryonic stem cell lines derived from human blastocysts. Science 1998; 282, 1145-7.

46. Reubinoff BE, Pera MF, Fong CY, Trounson A, Bongso, A. Embryonic stem cell lines from human blastocysts: somatic differentiation in vitro. Nature Biotechnol 2000; 18, 399 404

47. Takahashi K, Yamanaka S. Induction of pluripotent stem cells from mouse embryonic and adult fibroblast cultures by defined factors. Cell 2006; 126: 663-76.

48. Lander AD. The 'stem cell' concept: is it holding us back? J Biol 2009; $8: 70$

49. Tam PP, Loebel DA. Gene function in mouse embryogenesis: get set for gastrulation. Nat Rev Genet 2007; 8: 368-81.

50. Murry CE, Keller G. Differentiation of embryonic stem cells to clinically relevant populations: lessons from embryonic development. Cell 2008; 132: 661-80.

51. Rossant J, Tam PP. Blastocyst lineage formation, early embryonic asymmetries and axis patterning in the mouse. Development 2009; 136: 701-13.

52. Dulac C. Brain function and chromatin plasticity. Nature 2010; 465: 728 - 735

53. Meshorer E, Yellajoshula D, George E, Scambler PJ, Brown DT, Misteli T. Hyperdynamic plasticity of chromatin pro- teins in pluripotent embryonic stem cells. Developmental Cell. 2006; 10: 105-16.

54. Azuara V, Perry $P$, Sauer $S$, et al. Chromatin signatures of pluripotent cell lines. Nat Cell Biol. 2006; 8: 532-8.

55. Bernstein BE, Mikkelsen TS, Xie X, Kamal M, Huebert DJ, Cuff $\mathrm{J}$, et al. A bivalent chromatin structure marks key developmental genes in embryonic stem cells. Cell. 2006; 125: 315-26.

56. Abu-Remaileh M, Bergman Y. Epigenetic signature of embryonal stem cells: A DNA methylation perspective. Regulatory Networks in Stem Cells, Stem Cell Biology and Regenerative Medicine. New York: Humana Press; 2009. P. 247-56.

57. Laurent L, Wong E, Li G, Huynh T, Tsirigos A, Ong CT. et al. Dynamic changes in the human methylome during differentiation. Genome Res. 2010; 20: 320-31.

58. Lister R, Pelizzola M, Dowen RH, Hawkins RD, Hon G, TontiFilippini J, et al. Human DNA methylomes at base resolution show widespread epigenomic differences. Nature 2009; 462, 315-22

59. Meissner A, Mikkelsen TS, Gu H, Wernig M, Hanna J, Sivachenko A, et al. Genome-scale DNA methylation maps of pluripotent and differentiated cells. Nature 2008; 454, 766-70.

60. Faust C, Lawson KA, Schork NJ, Thiel B, Magnuson T. The Polycomb-group gene eed is required for normal morphogenetic movements during gastrulation in the mouse embryo. Development 1998; 125, 4495-4506.

61. Ku M, Koche RP, Rheinbay E, Mendenhall EM, Endoh M, Mikkelsen TS, et al. Genomewide analysis of PRC1 and PRC2 occupancy identifies two classes of bivalent domains. Plos Genet 2008; 4: e1000242.

62. Zhao XD, Han X, Chew JL, Liu J, Chiu KP, Choo A, et al. wholegenome mapping of histone H3 Lys 4 and 27 trimethylations reveals distinct genomic compartments in human embryonic stem cells. Cell Stem Cell 2007; 1, 286-98.

63. Pan G, Tian S, Nie J, Yang C, Ruotti V, Wei H, et al. wholegenome analysis of histone $\mathrm{H} 3$ lysine 4 and lysine 27 methylation in human embryonic stem cells. Cell Stem Cell 2007; 1, 299-312.

64. Mikkelsen TS, Ku M, Jaffe DB, Issac B, Lieberman E, Giannoukos $\mathrm{G}$, et al. Genome-wide maps of chromatin state in pluripotent and lineage-committed cells. Nature 2007; 448, 553-60.

65. Guenther MG, Levine SS, Boyer LA, Jaenisch, R. \& Young, R.A. A chromatin landmark and transcription initiation at most promoters in human cells. Cell 2007; 130, 77-88.

66. Heintzman ND, Stuart RK, Hon G, Fu Y, Ching CW, Hawkins $\mathrm{R}$, et al. Distinct and predictive chromatin signatures of transcriptional promoters and enhancers in the human genome. Nat. Genet. 2007; 39, 311-8.

67. Efroni S, Duttagupta R, Cheng J, Dehghani H, Hoeppner DJ, Dash $\mathrm{C}$, et al. Global transcription in pluripotent embryonic stem cells. Cell Stem Cell 2008; 2, 437-47.

68. Gu H, Bock C, Mikkelsen TS, Jäger N, Smith ZD, Tomazou E, et al. Genome-scale DNA methylation mapping of clinical samples at single-nucleotide resolution. Nat. Methods 2010; 7: 133-6.

69. Goren A, Ozsolak F, Shoresh N, Ku M, Adli M, Hart C, et al Chromatin profiling by directly sequencing small quantities ofimmunoprecipitated DNA. Nat. Methods 2010; 7, 47-9.

70. Bernstein BE, Stamatoyannopoulos JA, Costello JF, Ren B, Milosavljevic A, Meissner A, et al. The NIH Roadmap Epigenomics Mapping Consortium. Nat. Biotechnol. 2010; 28, $1045-8$.

71. Mohammad HP, Baylin SB. Linking cell signaling and the epigenetic machinery. Nat Biotechnol 2010; 28: 1033-8.

72. Hemberger M, Dean W, Reik W. pigenetic dynamics of stem cells and cell lineage commitment: digging Waddington's canal. Nat. Rev. Mol. Cell Biol. 2009; 10, 526-37.

73. Hochedlinger K, Plath K. Epigenetic reprogramming and induced pluripotency. Development 2009; 136: 509-23.

74. Zhou,Q, Melton DA. Extreme makeover: converting one cell into another. Cell Stem Cell 2008; 3: 382-8.

75. Yamanaka S, Blau HM. Nuclear reprogramming to a pluripotent state by three approaches. Nature 2010; 465: 704-12

76. Athanasiadou R, de Sousa D, Myant K, Merusi C, Stancheva I, Bird A. Targeting of de novo DNA methylation throughout the Oct- 4 gene regulatory region in differentiating embryonic stem cells. PLoS ONE 2010; 5: e9937.

77. Feldman N, Gerson A, Fang J, Li E, Zhang Y, Shinkai $Y$, et al. G9a-mediated irreversible epigenetic inactivation of Oct-3/4 during early embryogenesis. Nat. Cell Biol. 2006; 8: 18894.

78. Epsztejn-Litman S, Feldman N, Abu-Remaileh M, Shufaro $\mathrm{Y}$, Gerson A, Ueda J, et al. De novo DNAmethylation promoted by G9a prevents reprogramming of embryonically silenced genes. Nat. Struct. Mol. Biol. 2008; 15: 1176-83. 
79. Li JY, Pu MT, Hirasawa R, Li BZ, Huang YN, Zeng R, et al. Synergistic function of DNA methyltransferases Dnmt3a and Dnmt3b in the methylation of Oct4 and Nanog. Mol. Cell. Biol. 2007; 27: 8748-59.

80. Bhutani N, Brady JJ, Damian M, Sacco A, Corbel SY, Blau HM. Reprogramming towards pluripotency requires AIDdependent DNA demethylation. Nature 2010; 463: 1042-7.

81. Ito S, D'Alessio AC, Taranova OV, Hong K, Sowers LC, Zhang Y. Role of Tet proteins in $5 \mathrm{mC}$ to $5 \mathrm{hmC}$ conversion, ES-cell self-renewal and inner cell mass specification. Nature 2010; 466: 1129-33.

82. Sridharan R, Tchieu J, Mason MJ, Yachechko R, Kuoy E, Horvath S, et al. Role of the murine reprogramming factors in the induction of pluripotency. Cell 2009; 136: 364-77.

83. Lee TI, Jenner RG, Boyer LA, Guenther MG, Levine SS, Kumar $\mathrm{RM}$, et al. Control of developmental regulators by Polycomb in human embryonic stem cells. Cell 2006; 125: 301-13.

84. Marson A, Foreman R, Chevalier B, Bilodeau S, Kahn M, Young $\mathrm{RA}$, et al. Wnt signaling promotes reprogramming of somatic cells to pluripotency. Cell Stem Cell 2008; 3: 132-5.

85. Xu RH, Sampsell-Barron TL, Gu F, Root S, Peck RM, Pan G, et al. NANOG is a direct target of TGFbeta/activin-mediated SMAD signaling in human ESCs. Cell Stem Cell 2008; 3: 196-206.

86. Conti L, Pollard SM, Gorba T, Reitano E, Toselli M, Biella G, et al. Niche-independent symmetrical self-renewal of a mammalian tissue stem cell. PLoS Biol. 2005; 3: e283.

87. Brüstle O, Jones KN, Learish RD, Karram K, Choudhary K, Wiestler OD, et al. Embryonic stem cell-derived glial precursors: a source of myelinating transplants. Science 1999; 285: 754-6.

88. Niwa H, Burdon T, Chambers I, Smith, A. Self-renewal of pluripotent embryonic stem cells is mediated via activation of STAT3. Genes Dev. 1998; 12: 2048-60.

89. Niwa H, Ogawa K, Shimosato D, Adachi, K. A parallel circuit of LIF signalling pathways maintains pluripotency of mouse ES cells. Nature 2009; 460: 118-22.

90. Hirabayashi $\mathrm{Y}$, Itoh $\mathrm{Y}$, Tabata H, Nakajima K, Akiyama T, Masuyama $\mathrm{N}$, et al. The Wnt/beta-catenin pathway directs neuronal differentiation of cortical neural precursor cells. Development 2004; 131: 2791-2801.

91. Gunhaga L, Marklund M, Sjödal M, Hsieh JC, Jessell TM, Edlund T. Specification of dorsal telencephalic character by sequential Wnt and FGF signaling. Nat. Neurosci. 2003; 6 : 701-7.

92. Machon O, van den Bout CJ, Backman M, Kemler R, Krauss S. Role of beta-catenin in the developing cortical and hippocampal neuroepithelium. Neuroscience 2003; 122: 129-43.

93. Backman M, Machon O, Mygland L, van den Bout CJ, Zhong W, Taketo MM, et al. Effects of canonical Wnt signaling on dorso-ventral specification of the mouse telencephalon. Dev. Biol. 2005; 279: 155-68.

94. Maden M. Retinoic acid in the development, regeneration and maintenance of the nervous system. Nat. Rev. Neurosci. 2007; 8: 755-65.

95.Andrews PW. Retinoic acid induces neuronal differentiation of a cloned human embryonal carcinoma cell line in vitro. Dev. Biol. 1984; 103: 285-93.

96.Bertrand N, Dahmane N. Sonic hedgehog signaling in forebrain development and its interactions with pathways that modify its effects. Trends Cell Biol. 2006; 16: 597-605.

97. Jenuwein $T$, Allis CD. Translating the histone code. Science 2001; 293: 1074-80.

98. Richly $H$, Lange $M$, Simboeck E, Di Croce, L. Setting and resetting of epigenetic marks in malignant transformation and development. Bioessays 2010; 32: 669-79.

99. Klose RJ, Yan Q, Tothova Z, Yamane K, Erdjument-Bromage H,
Tempst $\mathrm{P}$, et al. The retinoblastoma binding protein RBP2 is an H3K4 demethylase. Cell 2007; 128: 889-900.

100. Pasini D, Hansen KH, Christensen J, Agger K, Cloos PA, Helin $\mathrm{K}$. Coordinated regulation of transcriptional repression by the RBP2 H3K4 demethylase and Polycomb-Repressive Complex 2. Genes Dev. 2008; 22: 1345-55.

101. Borggrefe T, Oswald F. Cell. Mol. The Notch signaling pathway: transcriptional regulation at Notch target genes. Life Sci. 2009; 66: 1631-1646.

102. Lin CH, Jackson AL, Guo J, Linsley PS, Eisenman RN. Mycregulated microRNAs attenuate embryonic stem cell differentiation. EMBO J. 2009; 28: 3157-70.

103. Dang CV. Micro-managing and restraining pluripotent stem cells by MYC. EMBO J 2009; 28: 3165-6.

104. Voog J, Jones DL. Stem cells and the niche: a dynamic duo. Cell Stem Cell 2010; 6: 103-15.

105. Eggan K, Baldwin K, Tackett M, Osborn, J, Gogos J, Chess A, et al. Mice cloned from olfactory sensory neurons. Nature $2004 ; 428,44-9$.

106. Hochedlinger $\mathrm{K}$, Jaenisch $\mathrm{R}$. Monoclonal mice generated by nuclear transfer from mature $\mathrm{B}$ and $\mathrm{T}$ donor cells. Nature $2002 ; 415,1035-8$.

107. Li J, Ishii T, Feinstein P, Mombaerts P. Odorant receptor gene choice is reset by nuclear transfer from mouse olfactory sensory neurons. Nature 2004; 428, 393-9.

108. Matsui $\mathrm{Y}$, Zsebo K, Hogan BL. Derivation of pluripotential embryonic stem cells from murine primordial germ cells in culture. Cell 1992; 70, 841-7.

109. Resnick JL, Bixler LS, Cheng L, Donovan PJ. Long-term proliferation of mouse primordial germ cells in culture. Nature 1992; 359, 550-1.

110. Xie H, Ye M, Feng R, Graf T. Stepwise reprogramming of B cells into macrophages. Cell 2004; 117, 663-76.

111. Davis RL, Weintraub $H$, Lassar $A B$. Expression of a single transfected cDNA converts fibroblasts to myoblasts. Cell 1987; 51, 987-1000.

112. Jaenisch R, Young R. Stem cells, the molecular circuitry of pluripotency and nuclear reprogramming. Cell 2008; 132, 567-82.

113. Maherali N, Ahfeldt T, Rigamonti A, Utikal J, Cowan C, Hochedlinger, K. A high-efficiency system for the generation and study of human induced pluripotent stem cells. Cell Stem Cell 2008; 3, 340-5.

114. Mikkelsen TS, Hanna J, Zhang X, Ku M, Wernig M, Schorderet $\mathrm{P}$, et al. Dissecting direct reprogramming through integrative genomic analysis. Nature 2008; 454, 49-55.

115. Okita K, Ichisaka T,Yamanaka S. Generation of germlinecompetent induced pluripotent stem cells. Nature 2007; 448, 313-7.

116. Wernig $M$, Meissner A, Foreman $R$, Brambrink $T, K u ~ M$, Hochedlinger $\mathrm{K}$, et al. In vitro reprogramming of fibroblasts into a pluripotent ES-cell-like state. Nature 2007; 448, 31824.

117. Hanna J, Markoulaki S, Schorderet P, Carey BW, Beard C, Wernig $\mathrm{M}$, et al. Direct reprogramming of terminally differentiated mature B lymphocytes to pluripotency. 2008; Cell 133, 250-64.

118. Kim JB, Zaehres H, Wu G, Gentile L, Ko K, Sebastiano V, et al. Pluripotent stem cells induced from adult neural stem cells by reprogramming with two factors. Nature $2008 ; 454,646$ 50 .

119. Viswanathan SR, Daley GQ, Gregory RI. Selective blockade of microRNA processing by Lin28. Science 2008; 320, 97 100.

120. Chang $\mathrm{HH}$, Hemberg $M$, Barahona $M$, Ingber DE, Huang, $\mathrm{S}$. Transcriptome-wide noise controls lineage choice in mammalian progenitor cells. Nature $2008 ; 453,544-7$. 
121. Huangfu D, Maehr R, Guo W, Eijkelenboom A, Snitow M, Chen $\mathrm{AE}$, et al. Induction of pluripotent stem cells by defined factors is greatly improved by small-molecule compounds. Nat. Biotechnol. 2008; 26, 795-7.

122. Huangfu D, Osafune K, Maehr R, Guo W, Eijkelenboom A, Chen $\mathrm{S}$, et al. Induction of pluripotent stem cells from primary human fibroblasts with only Oct4 and Sox2. Nat. Biotechnol. $2008 ; 26,1269-75$.

123. Boyer LA, Lee TI, Cole MF, Johnstone SE, Levine SS, Zucker $\mathrm{JP}$, et al. Core transcriptional regulatory circuitry in human embryonic stem cells. Cell 2005; 122, 947-56.

124. Dominguez-Sola D, Ying CY, Grandori C, Ruggiero L, Chen B, Li M, Galloway DA, et al. Non-transcriptional control of DNA replication by c-Myc. Nature $2007 ; 448,445-51$.

125. Knoepfler PS. Why myc? An unexpected ingredient in the stem cell cocktail. Cell Stem Cell 2008; 2, 18-21.

126. Lanza RP, Cibelli JB, West MD: Prospects for the use of nuclear transfer in human transplantation. Nat. Biotechnol.1999; 17: $1171-4$

127. Lanza RP, Cibelli JB, West MD: Human therapeutic cloning. Nat. Med. 1999; 5: 975-7.

128. Scholer HR. Octamania: the POU factors in murine development. Trends Genet. 1991; 7: 323-9.

129. Herr W, Cleary MA. The POU domain: versatility in transcriptional regulation by a flexible two-in-one DNA-binding domain. Genes Dev. 1995; 9: 1679-93.

130. Nichols J, Zevnik B, Anastassiadis K, Niwa H, Klewe-Nebenius $\mathrm{D}$, Chambers I, et al. Formation of pluripotent stem cells in the mammalian embryo depends on the POU transcription factor Oct4. Cell. 1998; 95: 379-91.

131. Niwa H, Miyazaki J, Smith AG. Quantitative expression of Oct$3 / 4$ defines differentiation, dedifferentiation or self-renewal of ES cells. Nat Genet. 2000; 24: 37372-6.

132. Chambers I, Colby D, Robertson $\mathrm{M}$, et al. Functional expression cloning of Nanog, a pluripotency sustaining factor in embryonic stem cells. Cell. 2003; 113: 643-55.

133. Mitsui $\mathrm{K}$, Tokuzawa $\mathrm{Y}$, Itoh $\mathrm{H}$, et al. The homeoprotein Nanog is required for maintenance of pluripotency in mouse epiblast and ES cells. Cell. 2003; 113: 631-42.

134. Darr H, Mayshar $Y$, Benvenisty N. Overexpression of NANOG in human ES cells enables feeder-free growth while inducing primitive ectoderm features. Development. 2006; 133: 1193-1201.

135. Avilion AA, Nicolis SK, Pevny LH, Perez L, Vivian N, Lovell-Badge R. Multipotent cell lineages in early mouse development depend on SOX2 function. Genes Dev. 2003; 17: 126-40.

136. Wood HB, Episkopou V. Comparative expression of the mouse Sox1, Sox2 and Sox3 genes from pre-gastrulation to early somite stages. Mech Dev. 1999; 86: 197-201.
137. Rowland BD, Peeper DS. KLF4, p21 and context-dependent opposing forces in cancer. Nat Rev Cancer. 2006; 6:11-23.

138. Knoepfler PS. Myc goes global: new tricks for an old oncogene. Cancer Res. 2007; v67: 5061-3.

139. Li Y, McClintick J, Zhong L, Edenberg HJ, Yoder MC, Chan RJ. Murine embryonic stem cell differentiation is promoted by SOCS-3 and inhibited by the zinc finger transcription factor Klf4. Blood. 2005;105: 635-7.

140. Cartwright P, McLean C, Sheppard A, Rivett D, Jones K, Dalton S. LIF/STAT 3 controls ES cell self-renewal and pluripotency by a Myc-dependent mechanism. Development. 2005; 132: 885-96.

141. Loh YH, Zhang W, Chen X, George J, Ng HH. Jmjd1a and Jmjd2C histone $\mathrm{H} 3$ Lys 9 demethylases regulate self-renewal in embryonic stem cells. Genes Dev. 2007; 21: 2545-57.

142. Richards M, Tan SP, Tan JH, Chan WK, Bongso A. The transcriptome profile of human embryonic stem cells as defined by SAGE. Stem Cells. 2004; 22: 51-64.

143. Gurdon JB. From nuclear transfer to nuclear reprogramming: the reversal of cell differentiation. Annu Rev Cell Dev Biol. 2006; 22: 1-22.

144. Tada M, Takahama Y, Abe K, Nakatsuji N, Tada T. Nuclear reprogramming of somatic cells by in vitro hybridization with ES cells. Curr Biol. 2001; 11: 1553-8.

145. Surani MA, Hayashi K, Hajkova P. Genetic and epigenetic regulators of pluripotency. Cell. 2007; 128: 747-62.

146. Aoi T, Yae K, Nakagawa M, Ichisaka T, Okita K, Takahashi K, et al. Generation of pluripotent stem cells from adult mouse liver and stomach cells. Science 2008; 321, 699-702.

147. Stadtfeld M, Brennand K, Hochedlinger, K. Reprogramming of pancreatic $\beta$ cells into induced pluripotent stem cells. Curr. Biol. 2008; 18, 890-894.

148. Yamanaka, S. Elite and stochastic models for induced pluripotent stem cell generation. Nature 2009; 460: 49-52.

149. Kim JB, Sebastiano V, Wu G, Araúzo-Bravo MJ, Sasse P, Gentile $\mathrm{L}$, et al. Oct4-induced pluripotency in adult neural stem cells. Cell 2009; 136, 411-9.

150. Graf T, Enver T. Forcing cells to change lineages. Nature 2009; 462: 587 - 594.

151. Yechoor V, Liu V, Espiritu C, Paul A, Oka K, Kojima H, et al.Neurogenin 3 is sufficient for transdetermination of hepatic progenitor cells into neo-islets in vivo but not transdifferentiation of hepatocytes. Dev. Cell 2009; 16, 35873.

152. Zhou Q,Brown J,Kanarek A, Rajagopal J, Melton DA. In vivo reprogramming of adult pancreatic exocrine cells to $\beta$-cells. Nature $2008 ; 455,627-32$. 